\title{
Apresentação - História da educação do corpo: pesquisas para uma noção em construção
}

\section{Presentation - History of the education of the body: research for a developing notion}

\author{
Evelise Amgarten Quitzau* \\ Andrea Moreno**
}

\begin{abstract}
RESUMO
Desde os anos 1980, o corpo vem se consolidando como um objeto de estudo das ciências humanas, inclusive da história, entre os adeptos da história cultural. As discussões geradas pelo chamado "giro corporal" ecoaram especialmente em áreas como a história da educação e história da educação física, do esporte e dos divertimentos, que direcionaram suas atenções para questões sobre como diferentes práticas e prescrições se desenvolveram, na sociedade ocidental moderna, com a finalidade de educar o corpo. A noção de educação do corpo, mobilizada em diferentes investigações, tem permitido novas interrogações sobre os mais diversos objetos de pesquisa, como manuais de ginástica e esporte, manuais de pintura, currículos de formação docente, ou mesmo os jogos e divertimentos ao ar livre. Neste texto introdutório, discutimos brevemente esta incorporação do corpo como objeto de estudos da história da educação, do esporte e dos divertimentos, indicando seu processo de consolidação e potencialidades para estes campos.

Palavras-chave: História. Corpo. Educação.
\end{abstract}

* Instituto Superior de Educación Física. Universidad de la República. Montevideo, Uruguay. E-mail: equitzau@cup.edu.uy - https://orcid.org/0000-0001-9789-6488

${ }^{* *}$ Universidade Federal de Minas Gerais. Faculdade de Educação. Programa de Pós-graduação em Educação. Belo Horizonte, Minas Gerais, Brasil. E-mail: andreafaeufmg@gmail.com - https:// orcid.org/0000-0002-3371-0282 


\begin{abstract}
Since the 1980s, the body is being consolidated as an object of study in humanities, including history, especially among those adept to cultural history. The debates generated by the so-called "corporeal turn" echoed powerfully in areas like the history of education and the history of physical education, sports, and amusements. This scholarship has focused on issues like the different practices and prescriptions developed in modern Western societies to educate the body. The notion of education of the body has been used by numerous scholars, allowing new interrogations over various research objects, such as handbooks on gymnastics and sports, handbooks on painting, curricula of teacher training programs, or even outdoor games and amusements. This introductory text briefly discusses this incorporation of the body as an object of study in the history of education, sports, and amusements, indicating its consolidation process and potentials for those areas.
\end{abstract}

Keywords: History. Body. Education.

O corpo se tornou um objeto de pesquisa que extrapolou os limites das ciências naturais e adentrou o campo das ciências humanas e, consequentemente, o domínio da história. Conforme Clever e Ruberg (2014), nos anos 1980 e 1990, o "giro corporal", oriundo especialmente da sociologia e da filosofia feminista contribuiu para consolidar o corpo como um objeto de estudo das ciências humanas, inclusive da história, onde encontrou grande recepção, especialmente entre os adeptos da história cultural.

Este interesse pelo corpo, entretanto, pode ser rastreado desde o início do século XX. Le Goff e Truong (2015) lembram que esse interesse começou pelas mãos de historiadores ligados à Escola de Annales, principalmente Lucien Febvre e Marc Bloch. Bloch inclusive afirmava que a história “(...) foi por muito tempo história despojada do seu corpo, da sua carne, de suas vísceras, de suas alegrias e desgraças. Seria preciso, portanto, dar corpo à história. E dar uma história ao corpo" (LE GOFF; TRUONG, 2015, p. 10). Segundo Le Goff e Truong (2015), a concepção de corpo, seu lugar na sociedade, sua presença no imaginário e na vida cotidiana sofreram modificações em todas as sociedades. Por isso, fazer a história do corpo era fazer uma história de um esquecimento.

Ao longo do século XX, diversos autores das ciências humanas contribuíram para a consolidação dessas "aventuras do corpo". Além dos já mencionados Lucien Febvre e Marc Bloch, podemos destacar o antropólogo francês Marcel Mauss, o sociólogo alemão Norbert Elias, os filósofos alemães Theodor Adorno e Max Horkheimer e o filosofo francês Michel Foucault. Parece haver um consenso de que especialmente os estudos de Elias sobre o processo 
civilizador e a obra de Foucault foram essenciais neste processo de transformação do corpo em objeto de estudo das ciências humanas (CLEVER; RUBERG, 2014; COOTER, 2010; GALÁN TAMÉS, 2009, SANT'ANNA, 1993). Estes autores contribuíram para colocar temas como as técnicas do corpo, as funções corporais e os diferentes mecanismos de repressão e controles dos impulsos corporais em lugar de destaque tanto de pesquisas historiográficas como sociológicas. Posteriormente, historiadores como Georges Duby, Paul Veyne e Jacques Le Goff também se mostraram atentos a uma história do corpo.

Esta consolidação do corpo como um objeto de estudo das ciências humanas em geral é bastante recente, ganhando força especialmente a partir das duas últimas décadas do século XX. Em texto publicado originalmente em 1991, quando este campo ainda estava em construção, Porter $^{1}$ apontava para a necessidade de "enxergar o corpo como ele tem sido vivenciado e expresso no interior de sistemas culturais particulares, tanto privados quanto públicos, por eles mesmos alterados através dos tempos" (PORTER, 1992, p. 295). Naquele momento, o autor nos alertava para o fato de que uma história do corpo não poderia ser limitada a pensar suas estatísticas físicas ou suas representações. Pensar uma história do corpo seria, para Porter, "um chamado para a compreensão da ação recíproca entre os dois" (PORTER, 1992, p. 301). Vinte anos mais tarde, ao revisitar o texto original, o autor mantém sua posição de que os estudos sobre a história do corpo deveriam atentar-se às interrelações entre representações e aspectos físicos. Ao analisar a produção referente a estas questões, aponta para a necessidade de não deixar que a história do corpo se reduza "a rastrear ainda mais formas por meio das quais o corpo tem sido inquirido, normalizado, disciplinado, policiado e punido" (PORTER, 2001, p. 237).

Observação similar é feita por Clever e Ruberg (2014, p. 550), ao afirmar que "nos últimos vinte anos, abordagens construcionistas sociais e discursivas sobre o corpo se tornaram muito influentes, mas também sofreram ataques devido a sua presumida falta de atenção à experiência corporal individual". Esta preocupação com uma ênfase potencialmente excessiva na questão dos discursos e representações sobre o corpo é compartida por Cooter (2010), ao apontar que alguns estudos da área, ao entender o corpo exclusivamente como uma representação, acabam transformando-o apenas em "atos discursivos", deixando de lado sua materialidade. Neste sentido, estes autores apontam para a necessidade de pensar não apenas as representações sobre o corpo, mas também as práticas que incidem sobre ele.

1 Roy Porter, History of the body, publicado em coletânea organizada por Peter Burke em 1991. Utilizamos aqui a tradução em português, publicada em 1992. 
Numerosos autores vêm se dedicando a pensar estas questões, e a variedade de publicações que abordam as numerosas práticas e representações sobre o corpo são um indício da consolidação desta temática no âmbito historiográfico. Exemplo disso é a coleção "Historie du corps", organizada pelos historiadores Alain Corbin, Jean-Jacques Courtine e Georges Vigarello e publicada no ano de 2005. Estes autores, acompanhados de Jean-Claude Schmitt, Jacques Revel, Jean-Jacques Courtine, entre outros, têm constituído a base teórica para as reflexões de pesquisadores brasileiros e sul-americanos que vêm se dedicando a investigar temas relacionados à história do corpo e, mais especificamente, dos processos que o educam.

Soares (2001) indica que o corpo é educado por toda a realidade que o circunda. A autora evidencia que a educação do corpo se trata de um fenômeno polissêmico e marcado por uma série de prescrições científicas e pedagógicas. Afinal, a educação do corpo “(...) dá-se não só por palavras, mas por olhares, gestos, coisas, pelo lugar onde vivem (SOARES, 2001, p. 110)". Neste, diferentes pedagogias foram estabelecidas tendo em vista diferentes objetivos e finalidades, principalmente aqueles ligados à educação e à saúde.

Nesse sentido, a noção de educação do corpo formalizada por Soares (2014) indica que a mesma se caracteriza pela progressiva repressão das manifestações corporais, tornando o corpo adequado ao convívio social, inserindo-o em processos de aprendizagens que buscam encobrir e apagar uma natureza rebelde e trazer à luz uma natureza pacificada. A autora salienta que, para ser exibido, o corpo precisa ser educado, e essas ações pedagógicas percorrem múltiplos caminhos, elaborando práticas contraditórias, ambíguas e tensas, que muitas vezes configuram verdadeiras formas de constrangimentos das pulsões.

No Brasil, assim como em alguns países sul-americanos, a noção de educação do corpo vem sendo trabalhada de forma sistemática e polissêmica no campo da Educação ao longo dos últimos anos, especialmente em pesquisas da corte historiográfico. Também no campo da Educação Física, área de formação inicial das duas organizadoras do presente dossiê, esse debate cresce e se adensa. Um número significativo de autores na área vem mobilizando noções, conceitos e ideias que tocam essas questões, de forma que é possível perceber, nos diversos fóruns acadêmicos e científicos, um crescente número de pesquisas, que resultam em publicações, dissertações e teses, sobre a história da educação do corpo, ou sobre os modos como os corpos vem sendo educados social e culturalmente pelas instituições, pelas práticas, por diversos dispositivos.

Para contar as histórias sobre essa educação, diverso material empírico tem sido mobilizado e se constituído como fontes pelas mãos de pesquisadores e grupos de pesquisa. Se, nos últimos 30 anos, muitas investigações, a partir de 
diferentes problematizações, vêm debruçando-se sobre esse inesgotável tema ${ }^{2}$, mais recentemente, nos últimos dez anos, percebemos também o indagar de novas questões, nascidas também em interface com diversos outros campos, como a Educação, a História, a Antropologia, as Artes, entre outros. Esse profícuo diálogo tem gerado perguntas diversas e novas hipóteses, para além daquelas que já há alguns anos permeiam o tema, potencializando contarmos outras histórias, que ainda estão por serem narradas. Nesse aspecto, ressaltamos os espaços destinados a debater a História da Educação Física, dos esportes, dos divertimentos, onde é nítida a problematização do campo.

O que este dossiê, ora organizado, nos revela? Que da escola ao circo, dos manuais de ginástica às histórias em quadrinhos, foram múltiplos os intentos de educar os corpos da população, especialmente de crianças e jovens. E essa multiplicidade se vê refletida nos 14 artigos selecionados para compor este dossiê. Com contribuições de autoras e autores de múltiplas regiões do país, assim como de argentinos, franceses e uruguaios, os artigos aqui reunidos olham para processos de educação do corpo a partir de diferentes fontes, recortes temporais e instituições, ora apontando para estes processos como mecanismos de disciplinamento, ora demonstrando como eram permeados por momentos de alegria e divertimento.

Em Educação do corpo - apontamentos para a historicidade de uma noção, artigo que abre este dossiê, Carmen Lúcia Soares tem como objetivo demonstrar como, em uma longa duração, diferentes sujeitos e instituições buscaram incidir na formação de processos educativos que tinham como finalidade intervir sobre o corpo, seus gestos e aparências. Para esta tarefa, mobiliza um variado conjunto de fontes produzidas entre os séculos XVII e XVIII, que permite visualizar como diferentes representações e formas de intervenções sobre o corpo foram se construindo nas sociedades ocidentais. Muitos destes preceitos estudados por Soares foram amplamente difundidos a partir de manuais de moral e higiene, e estes são justamente o principal objeto de estudo de Jacques Gleyse e Avelino Aldo de Lima Neto em Uma moral "corporal" generificada nos manuais escolares franceses de moral e de higiene (1880-1974). Os autores se debruçam sobre manuais escolares de moral

2 Os trabalhos de Carvalho e Correia (2015); Cunha (2017); Goellner (1992); Góis Júnior (2013, 2015); Jubé (2017); Melo e Peres (2014); Melo (2016); Moraes e Silva e Quitzau (2018); Moreno (2001, 2003, 2015, 2016); Naman, Furtado e Moraes e Silva (2020); Puchta (2015); Quitzau (2014, 2015, 2016); Quitzau e Soares (2016) e Soares (2000, 2004, 2015) são reveladores desse interesse. No exterior, podemos citar os estudos de Andrieu (1988,1999); Bui-Xuân e Gleyse (2001); Ljunggren (2011); Lundvall (2015); Rodríguez Giménez (2011); Sarremejane (2006); Scharagrodsky (2011). 
e higiene publicados na França, a partir de finais do século XIX, analisando como estas obras contribuíram, naquele período, para a construção de uma moral "generificada" a partir de prescrições bastante específicas sobre os corpos e comportamentos esperados de meninos e meninas. Poderíamos dizer que esta moral generificada, em certa medida, permanece na França ao longo do século XX. Conforme indicam Jean Saint-Martin e Nicolas Iffrig em Identidades masculinas, expressão corporal e educação física na França entre 1967 e 1985, a partir de uma análise exaustiva dos principais periódicos profissionais da área de educação física e esporte publicados na França, entre as décadas de 1960 e 1980, os embates entre o esporte hegemônico e as novas propostas que privilegiavam uma educação a partir da expressão corporal colocaram em disputa a representação da identidade masculina vigente neste período.

Esta relação entre uma moral generificada e a educação do corpo não era encontrada apenas em manuais escolares de moral e higiene, ou em revistas profissionais da área de Educação Física na França, mas também faziam parte dos próprios processos de formação de professores no Brasil. Em "Não pode casar ainda/ só depois que se formar": controle do corpo e formação de professoras normalistas na capital do Brasil (1920-1950), Fábio Souza Lima analisa uma série de normatizações vigentes na capital brasileira entre 1920 e 1950 que, em grande medida, se constituíam como formas de controle dos corpos das professoras normalistas formadas neste período, chegando a interferir, inclusive, na esfera privada da vida destas docentes.

Poderíamos dizer que uma das técnicas de educação do corpo que surgem ainda no século XIX é a ginástica, objeto de estudo explorado por Iara Marina dos Anjos Bonifácio e Anderson da Cunha Baía. Em Escritos de L.G. Kumlien e os indícios de variadas ginásticas suecas, Bonifácio e Baía analisam a difusão da ginástica sueca a partir da atuação de Ludvig Gideon Kumlien como divulgador das propostas elaboradas pelo Instituto Central de Ginástica de Estocolmo. A partir de manuais escritos por Kumlien e de notas publicadas em periódicos, os autores nos permitem compreender como a ginástica sueca, ao circular em contexto francês, ganhou novos contornos, transformando-se, assim, num novo método. Assim como a ginástica, os jogos ao ar livre também ocuparam lugar de destaque na França do início do século XX, especialmente no âmbito escolar. Em Jogos ao ar livre nas escolas primárias de Metz (1919-1932), Laurent Grün, ao analisar as escolas primárias de Metz, na fronteira entre França e Alemanha, evidencia como uma cultura física ao ar livre buscava contribuir para o desenvolvimento higiênico e moral das crianças, sem proporcionar distinções de gênero ou de religião, conformando um arcabouço de atividades pedagógicas menos estritas que aquelas tradicionalmente utilizadas pelos instrutores escolares. 
As preocupações higiênicas e suas relações com a educação dos corpos, entretanto, não são um produto dos manuais dos séculos XIX e XX, e podem ser encontrados em contextos brasileiros já no século XVIII, como demonstra Maria Cristina Rosa. No artigo Diversão, doença e educação dos corpos na comarca de Vila Rica (século XVIII), a autora se utiliza de um conjunto variado de fontes civis e eclesiásticas para nos conduzir às discussões sobre diversão e doença, entendidas como "faces de uma mesma moeda" que tinha no controle dos excessos corporais seu maior objeto de intervenção.

A circulação de manuais foi, provavelmente, uma das formas mais comuns de dar visibilidade a propostas de educação dos corpos. Se no século XIX e primeiras décadas do século XX a ginástica era o tema principal destas publicações, aos poucos ela começa a compartilhar (e mesmo perder) espaço para o esporte. Entre os diferentes métodos que passam a dar centralidade ao esporte está a Educação Física Esportiva Generalizada, desenvolvida na França, em meados do século XX, e que teve repercussões também na educação física brasileira. Em A produção da Education Physique Sportive Generalisée na França: o esporte como possibilidade educativa, Luciana Bicalho Cunha explora os principais autores e princípios que pautaram a criação deste método, indicando como ele conseguiu estabelecer os jogos e esportes como elementos centrais no ensino da educação física.

Discussões sobre o lugar da ginástica e do esporte na constituição da educação física foram centrais a partir da segunda metade do século XX, e influenciaram diretamente os currículos e a formação de professores na área. Isso é o que demonstram os artigos Los cambios curriculares desde los documentos oficiales en la formación del profesor de educación física en el Uruguay en la década del sesenta e Entre el "patio" y el "paper". Un análisis sobre las propuestas curriculares para la formación de profesores de Educación Física, Argentina (1970-1989), de Paola Dogliotti e Alejo Levoratti, respectivamente. Ambos tomam fontes oficiais para analisar e compreender os processos de constituição dos currículos de formação dos professores de educação física de seus países. Se, por um lado, Dogliotti se concentra nos debates que determinaram quais saberes deveriam fazer parte dos currículos de formação dos professores de educação física uruguaios, por outro, Levoratti indaga sobre como estes debates influenciaram a construção da identidade dos professores de educação física argentinos, em um período em que se começa a pensar as tensões entre pesquisa e ensino.

Os documentos oficiais, manuais de ginástica e as revistas profissionais não foram os únicos artefatos da cultura material a veicular determinadas normas a respeito do corpo. Como demonstra Eduardo Galak, a produção cinematográfica pode contribuir na profusão de determinados aspectos éticos e políticos sobre 
o corpo, e, desta maneira, serem tomados como fontes sobre a história dos processos de educação do corpo. Em Luz, cámara... educación del cuerpo y del carácter en el cine documental informativo de Max Glücksmann (1913-1915), o autor analisa como os documentários produzidos por este cineasta colocavam em jogo elementos de uma educação do corpo e das sensibilidades na Argentina que perpassavam tanto o âmbito escolar como a formação do soldado. Por sua vez, em Os quadrinhos de Caxuxa e suas mensagens às crianças: considerações a respeito do corpo infantil na revista "Cirandinha" (anos de 1950), Fernanda Theodoro Roveri e Maria Walburga do Santos se debruçam sobre outro artefato da cultura material de grande circulação: as revistas infantis. Tomando como objeto a revista Cirandinha, um importante instrumento de "instrução e diversão" de meninas no Brasil dos anos 1950, as autoras lançam seu olhar especialmente sobre os quadrinhos que contam a história de uma menina negra, Caxuxa, analisando como seus gestos e comportamentos permitem identificar uma série de elementos relacionados aos valores e lições difundidos em outras seções da revista. De maneira similar, no artigo Um dândi nos trópicos: esporte e educação do corpo nas crônicas de Paulo Barreto (João do Rio), André Mendes Capraro e Marcelo Moraes e Silva se utilizam de outro gênero literário como fontes para pensar a educação do corpo: as crônicas. Utilizando-se especialmente das produções de Paulo Barreto, mais conhecido como João do Rio, os autores analisam como o esporte é utilizado nestes textos para representarem diferentes elementos da sociedade carioca, fazendo emergir elementos educacionais que correspondiam diretamente ao corpo.

Assim como os documentos oficiais e manuais não foram os únicos veículos para difusão de determinados valores relacionados ao corpo, a educação formal não foi o único espaço em que se buscou intervir sobre os corpos com o objetivo de educá-los. Datado das primeiras décadas do século XX, o movimento escotista fundado por Baden-Powell encontrou um solo fértil no Brasil, como indica Andressa Barbosa de Farias Leandro em Na trilha da educação norterio-grandense: a emergência das práticas escoteiras na cidade do Natal no início do século $X X$. A partir de um amplo conjunto de fontes, a autora explora a emergência do escotismo potiguar, destacando as redes de sociabilidade que permitiram sua consolidação como um modelo de educação neste contexto.

Deixamos às leitoras e aos leitores o convite para explorar alguns retratos dos múltiplos processos de educação do corpo que se desenvolveram nos diferentes tempos e espaços históricos escolhidos e analisados pelos 14 estudos selecionados para a composição deste dossiê. 


\section{REFERÊNCIAS}

ANDRIEU, Gilbert. L'homme et la force. France: Editions Actio, 1988.

ANDRIEU, Gilbert. La Gymnastique au XIX Siècle ou a naissance de l'education physique (1789-1914). France: Editions Actio, 1999.

BUI-XUÂN, Gilles; GLEYSE, Jacques. De L'emergence de L'education physique: Georges Demeny et Georges Hebert - um modele conatif aplique au passé. Paris: Hatier, 2001.

CARVALHO, Luís Miguel; CORREIA, António Carlos. A recepção da Ginástica Sueca em Portugal nas primeiras décadas do século XX: conformidades e dissensões culturais e políticas. Revista Brasileira de Ciências do Esporte, Brasília, v. 37, n. 2, p. 136-143, 2015.

CLEVER, Iris; RUBERG, Willemijn. Beyond cultural history? The material turn, praxiography, and body history. Humanities, [s.l.], v. 3, p. 546-566, 2014.

COOTER, Roger. The turn of the body: history and the politics of the corporeal. Arbor Ciencia, Pensamiento y Cultura, Madrid, vol. 186, núm. 743, p. 393-405, 2010.

CORBIN, Alain; COURTINE, Jean-Jaques; VIGARELLO, Georges (dir.). Historie du corps. Paris: Seuil, 2005.

CUNHA, Luciana Bicalho da. A Educação Física Desportiva Generalizada no Brasil: princípios e sistematizações de um método de ensino em circulação (1952-1980). 2017. Tese (Doutorado em Educação) - Faculdade de Educação, Universidade Federal de Minas Gerais, Belo Horizonte, 2017.

LE GOFF, Jacques; TRUONG, Nicolas. Uma história do corpo na Idade Média. Rio de Janeiro: Record, 2015.

GALÁN TAMÉS, Genevieve. Aproximaciones a la historia del cuerpo como objeto de estudio de la disciplina histórica. Historia y Grafia, Ciudad de México, n. 33, p. 167-204, 2009.

GOELLNER, Silvana Vilodre. O método francês e a Educação Física: da caserna à escola. 1992. Dissertação (Mestrado em Educação Física) - Universidade Federal do Rio Grande do Sul, Porto Alegre, 1992.

GÓIS JÚNIOR, Edivaldo. Ginástica, higiene e eugenia no projeto de nação brasileira: Rio de Janeiro, século XIX e início do século XX. Movimento, Porto Alegre, v. 19. n. 1, p.139-159, jan./mar. 2013.

GÓIS JÚNIOR, Edivaldo. Georges Demeny e Fernando de Azevedo: uma ginástica científica e sem excessos (Brasil, França, 1900-1930). Revista Brasileira de Ciências do Esporte, Brasília, v. 37, p. 144-150, 2015.

JUBÉ, Carolina Nascimento. Educação, Educação Física e Natureza na obra de Georges Hébert e sua recepção no Brasil (1915-1945). 2017. Tese (Doutorado em Educação) Faculdade de Educação, Universidade Estadual de Campinas, Campinas, 2017. 
LJUNGGREN, Jens. ¿Por qué la gimnasia de Ling? El desarrollo de la gimnasia sueca durante el siglo XIX. In: SCHARAGRODSKY, Pablo (org.). La invención del "homo gymnasticus": Fragmentos históricos sobre la educación de los cuerpos en movimiento en Occidente. Buenos Aires: Prometeo, 2011. p. 37-52.

LUNDVALL, Suzanne. From Ling Gymnastics to Sport Science: The Swedish School of Sport and Health Sciences, GIH, from 1813 to 2013. The International Journal of The History of Sport, [s.l.], p. 789-799, abr. 2015.

MELO, Victor Andrade; PERES, Fabio de Farias. A Gymnastica no tempo do Império. Rio de Janeiro: 7 Letras, 2014.

MELO, Victor Andrade. Relações entre ginástica e saúde no Rio de Janeiro do século XIX: reflexões a partir do caso do Colégio Abílio, 1872-1888. Hist. cienc. saude-Manguinhos, Rio de Janeiro, v. 23, n. 4, p.1133-1151, 2016.

MORAES E SILVA, Marcelo; QUITZAU, Evelise Amgarten. A cultura física na cidade de Curitiba: a emergência de uma pedagogia corporal (1899-1909). Revista de Ciencias Sociales, Iquique, v. 27, n. 41, p. 275-296, 2018.

MORENO, Andrea. Corpo e ginástica num Rio de Janeiro - mosaico de imagens e textos. 2001. Tese (Doutorado em Educação) - Universidade Estadual de Campinas, Campinas, 2001.

MORENO, Andrea. O Rio de Janeiro e o corpo do homem fluminense: o 'não lugar' da ginástica sueca. Revista Brasileira de Ciências do Esporte, Campinas, v. 25, n. 1, p. 55-68, 2003.

MORENO, Andrea. A propósito de Ling, da ginástica sueca e da circulação de impressos em língua portuguesa. Revista Brasileira de Ciências do Esporte, Brasília, v. 37, p. 128-135, 2015.

MORENO, Andrea. O conhecido e hábil Pedro Manoel Borges: autor e professor de gymnastica (1876-1920). In: CONGRESSO LUSO-BRASILEIRO DE HISTÓRIA DA EDUCAÇÃO. 11., 2016, Porto. Actas [...]. Porto: FLUP, 2016. p. 130-144. Disponível em: http://web3.letras.up.pt/colubhe/actas/eixo6.pdf. Acesso em: 20 fev. 2021.

NAMAN, Maíra; FURTADO, Heitor Luis; MORAES E SILVA, Marcelo. Entre o rio e o mar: espaços de educação do corpo na cidade de Itajaí (1895-1920). Conexões, Campinas, v. 18, e020038, 2020. DOI: 10.20396/conex.v18i0.8660909. Disponível em: https://periodicos.sbu.unicamp.br/ojs/index.php/conexoes/article/view/8660909. Acesso em: 20 fev. 2021.

PORTER, Roy. História do corpo. In: BURKE, Peter. A escrita da história: novas perspectivas. São Paulo: Editora da Universidade Estadual Paulista, 1992. p. 291-326.

PORTER, Roy. History of the body revisited. In: BURKE, Peter. New perspectives on historical writings. Pennsylvania: The Pennsylvania State University Press, 2001. p. 233-260. 
PUCHTA, Diogo Rodrigues. A escolarização dos exercícios físicos e os manuais de ginástica no processo de constituição da Educação Física como disciplina escolar (1882-1926). 2015. Tese (Doutorado em Educação) - Universidade Federal de Minas Gerais, Belo Horizonte, 2015.

QUITZAU, Evelise Amgarten. A Ginástica Alemã: aspectos da obra de Friedrich Ludwig Jahn. Revista Brasileira de Ciências do Esporte, Brasília, v. 36, n. 2, p. 501-514, 2014.

QUITZAU, Evelise Amgarten. Da Ginástica para a juventude à ginástica alemã: observações acerca dos primeiros manuais alemães de ginástica. Revista Brasileira de Ciências do Esporte, Brasília, v. 37, p. 111-118, 2015. Disponível em: https://www.scielo.br/j/rbce/a/7 tt7mvGJXjLrWJxLGww8grm/?lang=pt\&format=pdf. Acesso em: 20 fev. 2021.

QUITZAU, Evelise Amgarten. Associativismo ginástico e imigração alemã no Sul e Sudeste do Brasil (1858-1938). 2016. 242 f. Tese (Doutorado em Educação) - Universidade Estadual de Campinas, Campinas, 2016.

QUITZAU, Evelise Amgarten; SOARES, Carmen Lúcia. Um manual do século XVIII: culto à natureza e educação do corpo em Ginástica para a Juventude, de Guts Muths. Revista Brasileira de História da Educação, Maringá, v. 16, n. 1, p. 23-50, jan./abr. 2016.

RODRÍGUEZ GIMÉNEZ, Raumar. Una conciencia y un corazón rectos en un cuerpo sano: educación del cuerpo, gimnástica y educación física en la escuela primaria uruguaya de la reforma. In: SCHARAGRODSKY, Pablo (comp.). La invención del "homo gymnasticus": Fragmentos históricos sobre la educación de los cuerpos en movimiento en Occidente. Buenos Aires: Prometeo, 2011. p. 477- 496.

SANT’ANNA, Denise Bernuzzi. Corpo e história. Cadernos de subjetividade, São Paulo, v. 1, n. 1, p.243-267, 1993.

SARREMEJANE, Philippe. L'heritage de la méthode suédoise d'éducation physique en France: les conflits de méthode au sein de l'Ecole normale de gymnastique et d'escrime de Joinville au début du XXème siècle. Revista Paedagogica Historica, [s.l.], v. 42, n. 6, p. 817-837, 2006.

SCHARAGRODSKY, Pablo (org.). La invención del "homo gymnasticus": Fragmentos históricos sobre la educación de los cuerpos en movimiento en Occidente. Buenos Aires: Prometeo, 2011. p. 441-475.

SOARES, Carmen Lúcia. Os Sistemas Ginásticos e a Formação da Educação Física Brasileira. In: CONGRESSO BRASILEIRO DE HISTÓRIA DA EDUCAÇÃO FÍSICA, ESPORTE, LAZER E DANÇA, 7., 2000, Gramado. Atas [...]. Gramado: UFRGS, 2000. v. 1, p. 44-52.

SOARES, Carmen Lúcia Corpo, conhecimento e educação: notas esparsas. In: SOARES, Camen Lúcia (org.). Corpo e história. Campinas: Autores Associados, 2001. p. 109-12.

SOARES, Carmen Lúcia. Educação Física: Raízes Européias e Brasil. 3 ed. Campinas: Autores Associados, 2004. 
QUITZAU, E. A.; MORENO, A. Apresentação-História da educação do corpo...

SOARES, Carmen Lúcia. Educação do corpo. In: GONZÁLEZ, Fernando Jaime; FENSTERSEIFER, Paulo Evaldo. Dicionário Crítico de Educação Física. Ijuí: Unijuí, 2014. p. 219-225.

SOARES, Carmen Lúcia. Uma educação pela natureza: o método de educação física de Georges Hébert. Revista Brasileira de Ciências do Esporte, Brasília, v. 37, p. 151-157, 2015.

Texto recebido em 28/03/2021.

Texto aprovado em 29/04/2021. 